\title{
Nasal Endoscopy and Computed Tomography for Epistaxis of Clinically Inapparent Aetiology
}

\author{
Reghunathan Rajesh ${ }^{1}$, Nair Anoop Narendran², Chrisanthus Jaya ${ }^{3}$ \\ ${ }^{1}$ Department of ENT, Government Medical College, Thiruvananthapuram, Kerala, India. \\ ${ }^{2}$ Department of ENT, Government Medical College, Thiruvananthapuram, Kerala, India. \\ ${ }^{3}$ Department of ENT, Government Medical College, Thiruvananthapuram, Kerala, India.
}

\section{ABSTRACT}

\section{BACKGROUND}

Epistaxis is one of the common otorhinolaryngological emergencies that are encountered in daily practice. Aetiology of epistaxis may range from benign conditions like septal spur, infected nasal polyps etc to serious causes like malignancies. Many a times, the cause for epistaxis is not found on anterior and posterior rhinoscopy. We wanted to assess the role of nasal endoscopy and computed tomography of paranasal sinuses (CT scan of PNS) among patients with epistaxis in whom the cause is not evident after history taking and clinical examination.

\section{METHODS}

This was a longitudinal study conducted in the Department of ENT in a tertiary care centre in south India. For patients included in the study, diagnostic nasal endoscopy under local anaesthesia was done and findings were noted. If any bleeding point was visualised on endoscopy, it was cauterised. In selected cases, endoscopic biopsy from nasal mass was done, and sent for histopathological examination. CT scan of PNS was done and findings were noted.

\section{RESULTS}

In the evaluation of patients with epistaxis of inapparent aetiology, nasal endoscopy could aid the diagnosis in $61.8 \%$ of patients, and CT scan of PNS in $81.8 \%$ of patients. Statistical comparison of measure of agreement between nasal endoscopy and CT scan of PNS for diagnosis of epistaxis of clinically inapparent aetiology yielded a kappa value of 0.187 which can be interpreted as slight agreement. Sensitivity of nasal endoscopy and CT scan for diagnosing sinonasal neoplasms as compared to histopathological examination (gold standard) was $83.3 \%$ and $100 \%$ respectively. Both had an accuracy of $66.7 \%$ as compared to histopathological examination. Statistical comparison of measure of agreement between nasal endoscopy and CT PNS for diagnosing sinonasal inflammation yielded a kappa value of 0.391 which can be interpreted as fair agreement.

\section{CONCLUSIONS}

For evaluation of sinonasal neoplasm causing epistaxis, CT scan of PNS has higher sensitivity than nasal endoscopy. Subclinical sinonasal infection could be a triggering factor for epistaxis in older patients. Nasal endoscopy and CT scan of paranasal sinuses are important and complementary tools in the evaluation of epistaxis.

\section{KEY WORDS}

Epistaxis, Nasal Endoscopy, CT Scan of Paranasal Sinuses, Sinonasal Neoplasm, Sinonasal Inflammation
Corresponding Author: Dr. Reghunathan Rajesh, Assistant Professor, Department of ENT, Government Medcial College, Thiruvananthapuram, Kerala, India. E-mail:drrrajeshent@gmail.com

DOI: $10.14260 /$ jemds/2020/507

How to Cite This Article:

Rajesh R, Narendran NA, Jaya C. Nasal endoscopy and computed tomography for epistaxis of clinically inapparent aetiology. J. Evolution Med. Dent. Sci. 2020;9(33): 2334-2339,

10.14260/jemds/2020/507

Submission 04-05-2020,

Peer Review 06-07-2020,

Acceptance 13-07-2020,

Published 17-08-2020.

Copyright (C) 2020 JEMDS. This is an open access article distributed under Creative Commons Attribution License [Attribution 4.0 International (CC BY 4.0)] 


\section{BACKGROUND}

Epistaxis is one of the common otorhinolaryngological emergencies that are encountered in daily practice. It is a common clinical symptom and not a specific diagnosis. Aetiology of epistaxis may range from benign conditions like septal spur, infected nasal polyps etc to serious causes like malignancies. According to studies conducted by Gilyoma et $\mathrm{al}^{1}$ and Chaiyasate et $\mathrm{al}^{2}$ the most common aetiology of epistaxis is trauma followed by infection of sinuses. Some of the areas of nose situated in the deep crevices of lateral wall of nose and nasopharynx are not visualized, and hence cause for epistaxis is not found out by anterior and posterior rhinoscopy. Diagnostic nasal endoscopy is essential in evaluation of the epistaxis patient. It is a simple procedure and can be done on OP basis. However, in some cases, endoscopic picture can be deceptive, especially when the main pathology is in the sinuses than in nasal cavity. According to the study by Anand Acharya et $\mathrm{al}^{3}$, patients with epistaxis should undergo imaging of paranasal sinuses, and according to Verma et $\mathrm{al}^{4}$ Computed Tomography is the modality of choice in imaging the paranasal sinuses (CT scan of PNS). The present study was undertaken to assess the effectiveness of Nasal endoscopy and CT scan of paranasal sinuses in cases of epistaxis where the cause of epistaxis was not revealed after history taking and clinical examination.

\section{Causes of Epistaxis 5}

\section{Local Causes}

Congenital

Unilateral choanal atresia, Meningocele, Encephalocele, Glioma.

\section{Acute Infections}

Viral, bacterial, fungal.

\section{Chronic Infections}

Specific (tuberculosis, syphilis, leprosy, rhinoscleroma) or non-specific: (rhinosporidiosis, ozaena, Wegener's granulomatosis, sarcoidosis).

\section{Inflammatory Causes}

Rhinosinusitis (allergic/vasomotor), nasal polyposis, Adenoiditis.

\section{Trauma}

Iatrogenic, facial trauma, foreign body, fingernail trauma in Little's area, fractures, hard blowing of nose.

\section{Benign Neoplasm}

Transitional cell papilloma, angiofibroma, haemangioma.

\section{Malignancy}

Squamous cell carcinoma, adenocarcinoma, adenoid cystic carcinoma, lymphoma, olfactory neuroblastoma, melanoma.

\section{Drug-Induced}

Rhinitis medicamentosa (topical decongestants/cocaine) Inhalants (tobacco, cannabis, heroin), mercury, phosphorus, wood dust.

\section{Atmospheric Changes}

High altitudes, Caisson's disease

\section{Septal Abnormalities}

\section{General Causes \\ Bleeding Disorders}

A. Coagulopathies

(i) Inherited: coagulation factor deficiencies, i.e. factor

VII (haemophilia A, B) and factor IX deficiency

(ii) Acquired: anticoagulants, liver disease, vitamin $\mathrm{K}$ deficiency, disseminated intravascular coagulation (DIC)

B. Platelet Disorders

1. Thrombocytopenia:

- Congenital.

- Acquired: marrow failure, i.e. aplasia, drugs, infiltration, increased consumption, immunemediated, DIC, hypersplenism, massive blood loss.

\section{Platelet Dysfunction}

- Congenital: Von Willebrand's disease, Bernard Soulier syndrome, Glanzmann's thrombasthenia.

- Acquired: myeloproliferative disease/leukaemia uraemia, dysparaproteinaemias.

- Drugs: aspirin, NSAIDs, Acquired storage pool disease.

C. Blood Vessel Disorders

- Congenital: osteogenesis imperfecta, hereditary haemorrhagic telangiectasia

- Acquired: amyloid, vasculitis, vitamin C deficiency

D. Hyperfibrinolysis

- Congenital: antiplasmin deficiency.

- Acquired: malignancy, DIC, fibrinolytic therapy.

\section{Cardiovascular Disorders}

Hypertension (contributing factor), arteriosclerosis, mitral stenosis, pregnancy-related

\section{Drugs}

Aspirin, Anticoagulants, Chloramphenicol, Methotrexate, Immunosuppressives, Alcohol, Dipyridamole

\section{Others}

Acute general infections, hepatic cirrhosis and liver failure, chronic nephritis, hypothyroidism, HIV, mediastinal compression, vicarious menstruation, idiopathic. 
We wanted to assess the role of nasal endoscopy and computed tomography among patients with epistaxis in whom the cause is not evident after history taking and clinical examination; We also wanted to study its effectiveness in diagnosing sinonasal inflammation and sinonasal neoplasm.

\section{METHODS}

This was a longitudinal study conducted in the Department of ENT in Govt. Medical College, Thiruvananthapuram which is a tertiary care centre in south India.

\section{Selection Criteria}

Patients admitted with epistaxis in the dept. of ENT, Govt. Medical College, Thiruvananthapuram in whom the aetiology was not evident after history taking and clinical examination were included. Patients who were not willing for nasal endoscopy or CT scan were excluded.

\section{Sample Size}

Minimum sample size calculated to be 110 by the formula $\mathrm{n}=$ $\left(\left[\mathrm{Z}_{1-@ / 2}\right]^{2} \mathrm{pq}\right) / \mathrm{d}^{2}$ where $\mathrm{p}=7 ; \mathrm{q}=(100-\mathrm{p})=93$ and $\mathrm{d}$ (absolute precision) $=5$ (study by Anil Markose $\mathrm{P}$ et $\mathrm{al}^{6}$ found the Proportion of epistaxis of inapparent aetiology to be 7\%)

\section{Methodology}

After getting clearance from the institutional ethical committee for research works and getting informed consent from the patients, history was elicited, general local and systemic examination were done, patients were stabilised, emergency treatment given and admitted. Blood investigations -blood routine, blood group, viral markers, bleeding parameters (bleeding time, clotting time, prothrombin time, activated partial thromboplastin time), lipid profile, peripheral smear, Liver function tests and Renal function tests were done. Patients were selected for the study according to inclusion and exclusion criteria. Diagnostic nasal endoscopy under local anaesthesia was done and findings noted. If any bleeding point was visualised on endoscopy, it was cauterised. In appropriate cases endoscopic biopsy from nasal mass was done, and sent for histopathological report (HPR), which is considered the gold standard in diagnosis. CT scan of paranasal sinuses was also done, and findings noted.
\end{abstract}

\section{Statistical Analysis}

All the data were entered into excel sheet and analysed using SPSS software version 22, and statistical variables like sensitivity and Kappa value were studied.

\section{RESULTS}

After excluding clinically evident cases like trauma, rhinosporidiosis and nasopharyngeal angiofibroma, 110 cases were included in the study.

\section{I (A) History and Clinical Examination}

The incidence of epistaxis was more after forty years. The maximum number of cases was in the age group 51-60 years. In our study, 75 were males and 35 were females with the ratio of 2.1:1. Most of the cases had unilateral nasal bleed. $56.4 \%$ of cases had anterior nasal bleed, while $43.6 \%$ cases had both anterior and posterior nasal bleed. Most of the patients had recurrent episodes. 70\% cases had bleed of less than 1-month duration. Several patients had more than one addiction. $30.9 \%$ patients were alcoholics, $22.7 \%$ patients were smokers, and $2.7 \%$ patients had used nasal snuff.

\section{I (B) Treatment Given}

Majority $(63.6 \%)$ of patients underwent nasal packing to control bleed. Endoscopic cauterization was done in $14.5 \%$ of patients, while $21.9 \%$ patients were treated conservatively. Most of the patients underwent anterior nasal packing with Merocel or medicated gauze. Only 3 patients required postnasal packing to control nasal bleed.

\section{I (C) Nasal Endoscopy Findings}

Several patients had more than one finding on nasal endoscopy. On endoscopy 38 patients (34.5\%) had features suggestive of sinonasal inflammation (nasal discharge, nasal polyp and polypoidal middle turbinate -one or more of these). Mucosal oedema was not taken into consideration as many patients had recent nasal packing. Finding suggestive of sinonasal tumours were seen in 7 patients.

\begin{tabular}{|ccc|}
\hline Nasal Endoscopy Findings & Frequency & $\begin{array}{c}\text { Percentage } \\
\text { (N=110) }\end{array}$ \\
Nasal discharge (mucopurulent) & 29 & 26.3 \\
Nasal discharge (allergic mucin) & 4 & 3.6 \\
Nasal discharge (fungal debris in middle meatus) & 2 & 1.8 \\
Nasal polyp & 26 & 23.6 \\
Polypoidal middle turbinate & 9 & 8.1 \\
Mass lesions (tumours) & 5 & 4.5 \\
Lateral wall bulge (with probable underlying & 2 & 1.8 \\
tumour) & 16 & 14.5 \\
Bleeding points & 5 & 4.5 \\
Dilated and tortuous vessels & 28 & 25.4 \\
Deviated nasal septum with spur & 5 & 4.5 \\
Enlarged adenoids & 42 & 38.2 \\
Normal & \\
\hline Table 1. Nasal Endoscopy Findings \\
\hline
\end{tabular}

\section{I (D) CT Scan Findings}

Several patients had more than one finding on CT scan. Majority of patients (57.2\%) had sinonasal inflammation as evident from mucosal thickening, sinus opacification and blockage of ostiomeatal units. Features of sinonasal neoplasm was seen in 9 patients (details given in table 3 ).

Cause of epistaxis was evident after nasal endoscopy in 68 (61.8\%) patients. Cause of epistaxis was evident after CT scan in $90(81.8 \%)$ patients. 12 patients $(10.9 \%)$ had both nasal endoscopy and CT PNS findings reported as normal.

\begin{tabular}{|ccc|}
\hline CT Scan Finding & Frequency & Percentage (n=110) \\
Sino nasal inflammation & 63 & 57.2 \\
Features of AFRS & 12 & 10.9 \\
(Allergic Fungal Rhino Sinusitis) & 5 & 4.5 \\
Fungal ball & 4 & 3.6 \\
Sino nasal neoplasm (benign) & 5 & 4.5 \\
Sino nasal neoplasm (malignant) & 28 & 25.4 \\
Deviated nasal septum with spur & 5 & 4.5 \\
Enlarged adenoids & 20 & 18.1 \\
Normal & \\
\hline Table 2. CT Scan Findings \\
\hline
\end{tabular}


II (A) Sino Nasal Tumours - Comparison of Endoscopic Findings, CT Paranasal Sinus Findings and HPR

\begin{tabular}{|c|c|c|c|}
\hline & $\begin{array}{l}\text { CT-PNS } \\
\text { Findings }\end{array}$ & Nasal Endoscopic Findings & $\begin{array}{l}\text { Histopathology } \\
\text { Findings }\end{array}$ \\
\hline A & $\begin{array}{c}\text { Benign } \\
\text { neoplasm }\end{array}$ & $\begin{array}{l}\text { Reddish polypoid mass attached to } \\
\text { posterior third of inferior turbinate. }\end{array}$ & Malignant melanoma \\
\hline B & $\begin{array}{l}\text { Benign } \\
\text { neoplasm }\end{array}$ & Bulge in lateral wall & Chronic inflammation \\
\hline $\mathrm{C}$ & $\begin{array}{c}\text { Benign } \\
\text { neoplasm }\end{array}$ & Reddish mass in middle meatus & Haemangioma \\
\hline D & $\begin{array}{c}\text { Benign } \\
\text { neoplasm }\end{array}$ & Mass in middle meatus & $\begin{array}{c}\text { Sino nasal papilloma } \\
\text { oncocytic variant }\end{array}$ \\
\hline $\mathrm{E}$ & $\begin{array}{l}\text { Malignant } \\
\text { neoplasm }\end{array}$ & Bulge in lateral wall & Plasmacytoma \\
\hline $\mathrm{F}$ & $\begin{array}{l}\text { Malignant } \\
\text { neoplasm }\end{array}$ & Mass in sphenoethmoidal recess & $\begin{array}{l}\text { Rosai Dorfman } \\
\text { disease }\end{array}$ \\
\hline G & $\begin{array}{l}\text { Malignant } \\
\text { neoplasm }\end{array}$ & Mass in middle meatus & $\begin{array}{c}\text { Chronic } \\
\text { granulomatous } \\
\text { disease }\end{array}$ \\
\hline $\mathrm{H}$ & $\begin{array}{l}\text { Malignant } \\
\text { neoplasm }\end{array}$ & Multiple polyps in middle meatus. & Inflammatory polyp \\
\hline I & $\begin{array}{l}\text { Malignant } \\
\text { neoplasm }\end{array}$ & Polyp in sphenoethmoidal recess & $\begin{array}{c}\text { Undifferentiated Sino } \\
\text { nasal malignancy }\end{array}$ \\
\hline \multicolumn{4}{|c|}{ Table 3. Sinonasal Tumours } \\
\hline
\end{tabular}

II (B) Comparison of Endoscopic Findings with HPR for Sinonasal Tumours

Sensitivity of nasal endoscopy for diagnosing sinonasal neoplasms as compared to histopathological examination (gold standard) was $83.3 \%$. Accuracy of nasal endoscopy as compared to histopathological examination was $66.7 \%$.

\begin{tabular}{|cccccc|}
\hline Endoscopy & Positive & Negative & Sensitivity & PPV & Accuracy \\
\hline Positive & 5 & 2 & $83.3 \%$ & $71.4 \%$ & $66.7 \%$ \\
Negative & 1 & 1 & & & \\
\hline \multicolumn{5}{|c|}{ Table 4. Comparison of Endoscopic Findings with HPR } \\
For Sinonasal Neoplasms \\
\hline \multicolumn{5}{|c|}{} \\
\hline
\end{tabular}

\section{II (C) Comparison of CT - PNS with HPR for Sinonasal} Tumours

Sensitivity of computed tomography for diagnosing sinonasal neoplasm compared to histopathological examination (gold standard) was $100 \%$ because CT scan had detected all the neoplasms which were diagnosed by histopathological examination.

\begin{tabular}{|cccccc|}
\hline \multirow{2}{*}{ CT PNS } & Positive & Negative & Sensitivity & PPV & Accuracy \\
\hline Positive & 6 & 3 & $100.0 \%$ & $66.7 \%$ & $66.7 \%$ \\
Negative & 0 & 0 & & \\
\hline \multicolumn{5}{|c|}{ Table 5. Comparison of CT Scan Findings with HPR } \\
for Sinonasal Neoplasms \\
\hline \multicolumn{5}{|c}{} \\
\hline
\end{tabular}

\section{Sinonasal Inflammation - Comparison of Endoscopy \& CT Scan Findings}

Sinonasal inflammation was diagnosed with endoscopy alone in $5(4.5 \%)$ cases, with CT scan - PNS alone in $30(27.3 \%)$ cases and with both endoscopy and CT scan - PNS in 33 (30\%) cases. Endoscopic findings suggestive of sinonasal inflammation were found in 38 cases.

\begin{tabular}{|c|c|c|c|c|c|}
\hline $\begin{array}{c}\text { CT-PNS } \\
\text { Shows } \\
\text { Sinonasal } \\
\text { Inflammation }\end{array}$ & $\begin{array}{c}\text { Nasal Endoscopy } \\
\text { Shows Sinonasal } \\
\text { Inflammation }\end{array}$ & Agreement & $\begin{array}{c}\text { Kappa } \\
\text { Value }\end{array}$ & Interpretation \\
\cline { 2 - 3 } Present & 33 & 30 & & $\begin{array}{c}0.391 \\
(95 \% \mathrm{CI} \\
0.240 \mathrm{TO} \\
0.542)\end{array}$ & Fair agreement \\
\hline Absent & 5 & 42 & 68.18 & $\begin{array}{c}\text { Absent } \\
\text { Table 6. Comparison of Endoscopy and CT Scan Findings } \\
\text { In Sinonasal Inflammation }\end{array}$ \\
\hline \multicolumn{7}{|c|}{} \\
\hline
\end{tabular}

Statistical comparison of measure of agreement between nasal endoscopy and CT PNS for sinonasal inflammation yielded a kappa value of 0.391 which can be interpreted as fair agreement.

IV Comparison of Endoscopy \& CT - PNS for Diagnosis of Epistaxis of Clinically Inapparent Aetiology

Among the 110 patients, diagnosis of epistaxis of clinically unclear aetiology was possible with nasal endoscopy alone in $68(61.8 \%)$ cases, with CT scan - PNS alone in 90 (81.8\%) cases, and after both endoscopy and CT scan in 98 (89\%) cases. No diagnosis was attained after endoscopy and CT PNS in 12 (11\%) cases.

Statistical comparison of measure of agreement between nasal endoscopy and CT PNS for diagnosis of epistaxis of clinically inapparent etiology yielded a kappa value of 0.187 which can be interpreted as slight agreement.

\begin{tabular}{|c|c|c|c|c|c|}
\hline \multirow{2}{*}{ CT PNS } & \multicolumn{2}{|c|}{ Nasal Endoscopy } & \multirow{2}{*}{ Agreement } & \multirow{2}{*}{$\begin{array}{c}\text { Kappa } \\
\text { Value }\end{array}$} & \multirow{2}{*}{ Interpretation } \\
\hline & Normal & Abnormal & & & \\
\hline Normal & 12 & 8 & \multirow[b]{2}{*}{$65.45 \%$} & 0.187 & \multirow[b]{2}{*}{ Slight agreement } \\
\hline Abnormal & 30 & 60 & & $\begin{array}{c}(95 \% \text { CI } \\
0.015 \text { TO } \\
0.359)\end{array}$ & \\
\hline & $\begin{array}{l}\text { Cor } \\
\text { Epis }\end{array}$ & $\begin{array}{l}\text { ison of } 1 \\
\text { of Clini }\end{array}$ & scopy ar & T Scan & ndings in \\
\hline
\end{tabular}

\section{DISCUSSION}

\section{I (A) History and Clinical Examination}

In our study majority of the patients were above 40 years (73.6\%) with peak age group of $50-60$ years (24.5\%). This is comparable to the study by $\mathrm{M} \mathrm{T}$ Anie et $\mathrm{al}^{7}$ in which epistaxis was more common above the age of 60 years. According to study by Pope LE et al ${ }^{8}$, there is a bimodal age distribution of epistaxis with peaks in children and the older adults (45-65 years).

In this study, $68.2 \%$ patients were males and $31.8 \%$ were females with 2.1:1 ratio in favour of males. Study conducted by Gilyoma JM et al ${ }^{1}$ described male to female ratio of 2.7:1. In the study by A M Kodiya ${ }^{9}$ slight male preponderance with a male to female ratio of 1.4:1 was seen. Nasal bleed was unilateral in $58 \%$ (64 patients) and bilateral in $42 \%$ (46 patients). In the study by Varshney et $\mathrm{al}^{10}$, bleeding was unilateral in $87.5 \%$ of cases and bilateral in $12.5 \%$ of cases. In our study 25 cases $(22.7 \%)$ were smokers and 34 cases $(30.9 \%)$ were alcoholic. Varshney et al ${ }^{10}$ observed in their study that $26 \%$ were smokers and $27 \%$ were alcoholic.

\section{I (B) Treatment}

In our study, epistaxis was controlled by nasal packing in $63.6 \%$ of patients, $14.5 \%$ patients underwent endoscopic 
cauterization while $21.9 \%$ patients were treated symptomatically with digital pressure, nasal decongestants and use of drugs promoting coagulation like tranexamic acid. In a study by Vis $\mathrm{E}$ et $\mathrm{al}^{11}$ to determine treatment of epistaxis with cautery, nasal bleed in $98 \%$ of patients was controlled by cautery and the study stated that cauterisation was more effective and efficient than nasal packing.

\section{I (C) Nasal Endoscopy Findings}

On endoscopy, bleeding points were found in 16 patients $(14.5 \%)$ out of which 7 patients $(6.4 \%)$ had bleeding from sphenopalatine area, 5 patients $(4.5 \%)$ had bleeding from middle turbinate while 4 patients $(3.6 \%)$ had bleeding from posterior part of septum. In the study by Swapna UP et al ${ }^{12}$ $12 \%$ patients had bleeding points and all of them had bleeding points in nasal septum. In a study by Vinaykumar et al ${ }^{13}$ the commonest bleeding point was in lateral nasal wall $(28 \%)$, followed by posterior part of septum (4\%).

Mucopurulent discharge was the commonest significant nasal endoscopic finding in our study. $17.3 \%$ of patients had mucopurulent discharge in middle meatus, while $9 \%$ patients had mucopurulent discharge in sphenoethmoidal recess. In a study by Seidel DU et al, ${ }^{14}$ epistaxis was found to be positively related with discharge due to chronic sinusitis.

Nasal polyps were seen in $23.6 \%$ of cases in our study. In the study by Swapna UP et al,12 $10 \%$ of patients had nasal polyps. In the study done by Jahromi MA et al ${ }^{15}$ to determine frequency of presenting symptoms of nasal polyps, $11.1 \%$ of patients with nasal polyps presented with epistaxis.

$25.4 \%$ of patients in this study had deviated nasal septum with spur which is similar to study by Vinaykumar et $\mathrm{al}^{13}$ in which $24 \%$ patients had deviated nasal septum with spur. $4.5 \%$ of patients had enlarged and congested adenoids compared to $8 \%$ in the study done by Swapna U.P et al. ${ }^{12}$

$4.5 \%$ of patients in this study had dilated and tortuous vessels in Woodruff's plexus. In a research done by Han HC 16 clinical observations have linked tortuous arteries and veins with aging, atherosclerosis, hypertension, genetic defects and diabetes mellitus.

In our study $38.2 \%$ patients had normal endoscopy findings. This is comparable to a study done by Manickam A et al 17 , in which $37 \%$ of patients had normal endoscopic findings and a study by Rehman A et al ${ }^{18}$ in which $30 \%$ cases had normal endoscopic findings.

\section{I (D) CT Scan Findings}

In this study $81.8 \%$ of patients had significant CT scan findings. Features of sinonasal inflammation were seen in $57.2 \%$ of patients. In a study conducted by Horn $\mathrm{N}$ van et al ${ }^{19}$, $47.3 \%$ of patients with recurrent epistaxis had CT scan findings of sinonasal inflammation.

\section{Sino Nasal Tumours}

In this study $6.3 \%$ of patients had endoscopic findings suggestive of sinonasal neoplasm (mass lesions and lateral wall bulge). In a study done by Vinaykumar, et al ${ }^{13}, 4 \%$ of patients had endoscopic findings suggestive of neoplasm. Sensitivity of nasal endoscopy for diagnosing sinonasal neoplasms as compared to histopathological examination (gold standard) was $83.3 \%$.
In the present study $8.1 \%$ of patients had CT scan findings of neoplasm. In a study conducted by Horn $\mathrm{N}$ van et al ${ }^{19}, 52.6$ $\%$ of patients presenting with recurrent epistaxis had neoplasms in CT scan. According to our study, the sensitivity of computed tomography for diagnosing sinonasal neoplasm compared to histopathological examination (gold standard) was $100 \%$ and accuracy was $66.7 \%$.

\section{Sinonasal Inflammation}

In our study on comparison between nasal endoscopy and CT scan PNS for features suggestive of sinusitis, $34.5 \%$ patients had features suggestive of sinonasal inflammation on endoscopy while $57.2 \%$ of patients showed sinonasal inflammation on CT scan. 30 patients with sinonasal inflammation on CT scan had normal findings on endoscopy. This disparity may be due to the fact that mucosal oedema was not taken into consideration while doing nasal endoscopy in our study and some of the patients possibly had subclinical sinus infections.

One case of polyp in sphenoethmoidal recess on endoscopy showed features of malignancy of sphenoid sinus with intracranial extension in CT-PNS, and biopsy showed sinonasal malignancy of undifferentiated type. Another patient who presented with severe recurrent epistaxis had multiple polyps in left middle meatus on endoscopy, and on CT-scan, had features suggestive of malignancy, but histopathology showed only inflammatory polyp.

In the study by Deosthale $\mathrm{NV}$ et $\mathrm{al}^{20}$, out of 54 study patients with chronic rhinosinusitis, 45 (83.33\%) had abnormal endoscopic examination while 50 (92.59\%) were having positive CT scan findings, and the study concludes a high correlation between the two.

\section{Comparison of Endoscopy \& CT - PNS for the Diagnosis of Epistaxis of Clinically Inapparent Aetiology}

On statistical comparison of nasal endoscopy and computed tomography in diagnosis of epistaxis of clinically inapparent etiology, kappa value $<0.2$ was obtained showing only slight agreement. This can be attributed to high sensitivity of computed tomography in diagnosing cases of sinonasal inflammation and sinonasal neoplasm.

\section{CONCLUSIONS}

In the evaluation of patients with epistaxis of inapparent aetiology, nasal endoscopy could aid the diagnosis in $61.8 \%$ of patients and CT scan of paranasal sinus in $81.8 \%$ of patients. For evaluation of sinonasal neoplasm causing epistaxis, CT scan of paranasal sinuses has higher sensitivity than nasal endoscopy. Majority of the patients were above the age of 40 years (73.6\%). In majority of the patients (57.2\%) CT scan findings showed sinonasal inflammation of which $27.3 \%$ of patients had normal endoscopy. So, it can be presumed that a subclinical sinonasal infection could be a triggering factor for epistaxis in older patients. Nasal endoscopy and CT scan of paranasal sinuses are important and complementary tools in the evaluation of epistaxis. 
Financial or Other Competing Interests: None.

\section{REFERENCES}

[1] Gilyoma JM, Chalya PL. Etiological profile and treatment outcome of epistaxis at a tertiary care hospital in Tanzania: a prospective review of 104 cases. BMC Ear Nose Throat Disord 2011;11:8.

[2] Chaiyasate S, Roongrotwattanasiri K, Fooanan S, et al. Epistaxis in Chiang Mai University hospital. J Med Assoc Thai 2005;88(9):1282-6.

[3] Acharya A, Lakhpati G. CT of para nasal sinuses (PNS) - a surgeon's view point. IAIM 2015;2(11):39-45.

[4] Verma J, Rathaur SK, Mishra S, et al. The role of diagnostic imaging in evaluation of nasal and paranasal sinus pathologies. Int J Otorhinolaryngol Head Neck Surg 2016;2(3):140-6.

[5] Watkinson JC. Epistaxis. Chap- 18. In: Mackay IS, Bull TR, eds. Rhinology, Scott brown's otorhinolaryngology head and neck surgery. $6^{\text {th }}$ ed. Oxford: Butterworth Heinemann 1998:942-61.

[6] Anil MP, Rony KMT, George S. Epistaxis: a clinical study of 200 cases in a tertiary hospital - our experience. Journal of Evolution of Medical and Dental Sciences 2014;3(17):4441-5.

[7] Anie MT, Arjun GM, Andrews CJ, et al. Descriptive epidemiology of epistaxis in a tertiary care hospital. Int J Adv Med 2015;2(3):255-9.

[8] Pope LER, Hobbs CGL. Epistaxis: an update on current management. Postgrad Med J 2005;81(955):309-14.

[9] Kodiya AM, Labaran AS, Musa E, et al. Epistaxis in Kaduna, Nigeria: a review of 101 cases. Afr Health Sci 2012;12(4):479-82.

[10] Varshney S, Saxena RK. Epistaxis: a retrospective clinical study. Indian J Otrolaryngol Head Neck Surg 2005;57(2):125-9.
[11] Vis E, van den Berge H. Treatment of epistaxis without the use of nasal packing, a patient study. Rhinology 2011;49(5):600-4.

[12] Swapna UP, Simla SR, Anjali R, et al. Endoscopic evaluation and treatment of epistaxis - a prospective study. Int J Med Res Rev 2016;4(6):971-5.

[13] Kumar MVV, Prasad KUR, Gowda PRB, et al. Rigid nasal endoscopy in the diagnosis and treatment of epistaxis. J Clin Diagn Res 2013;7(5):831-3.

[14] Seidel DU, Jacob L, Kostev K, et al. Risk factors for epistaxis in patients followed in general practices in Germany. Rhinology 2017;55(4):312-8.

[15] Jahromi MA, Pour AS. The epidemiological and clinical aspects of nasal polyps that require surgery. Iran J Otorhinolaryngol 2012;24(67):75-8.

[16] Han HC. Twisted blood vessels: symptoms, etiology and biomechanical mechanisms. J Vasc Res 2012;49(3):18597.

[17] Manickam A, Ghosh D, Saha J, et al. An aetiopathological study on epistaxis in adults and its management. Bengal Journal of Otorhinolaryngoly and Head Neck Surgery 2015;23(1):12-7.

[18] Rehman A, Rafiq F, Hussain B. Epistaxis-assessment of aetiology and effectiveness of treatment modalities. PJMHS 2015;9(2):689-92.

[19] van Horn N, Faizy TD, Schoenfeld MH, et al. Computed tomography findings in patients with primarily unknown causes of severe or recurrent epistaxis. PLoS One 2019;14(8):e0220380.

[20] Deosthale NV, Khadakkar SP, Harkare VV, et al. Diagnostic accuracy of nasal endoscopy as compared to computed tomography in chronic rhinosinusitis. Indian J Otolaryngol Head Neck Surg 2017;69(4):494-9. 